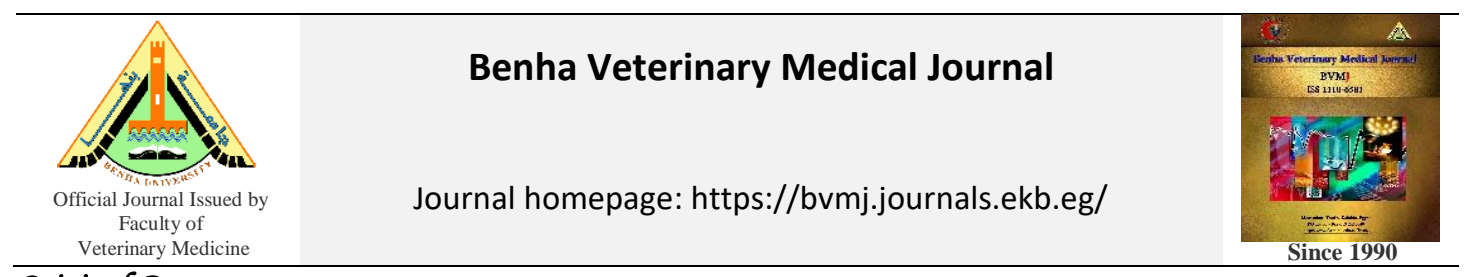

Original Paper

\title{
Incidence of Staphylococcus enterotoxins in some meals served in Egyptian hotel
}

Osama. M. Abbass, Saad. M. Saad, Mohammed A. Hassan, Walid. S. Arab

Department of Food Hygiene and control, Faculty of Veterinary Medicine, Benha University.

\section{ARTICLE INFO}

Keywords

Streptococcus enterotoxins

meals

Hotels

Received 23/07/2021

Accepted 27/07/2021

Available On-Line

$01 / 10 / 2021$

\begin{abstract}
A total 120 random samples of beef kofta, chicken panne and fish based meal (sushi) (40 of each), served in Egyptian hotels located in Cairo Governorate, Egypt were collected to determine of $S$. aureus counts, isolation , identifications and detection of their enterotoxins in the examined samples. The obtained results revealed that $S$. epidermidis, S. intermedius, $S$. saprophyticus and S. xylosuswere recorded in (25\%), $(2.5 \%),(0 \%)$ and $(12.5 \%)$ of Kofta, while for chicken panne were detected $(37.5 \%),(10 \%),(7.5 \%)$ and $(2.5 \%)$, in add to $(45 \%)$, $(17.5 \%),(5 \%)$ and $(10 \%)$ were detected in Sushi fish samples, furthermore S. aureus was detected in $13(32.5 \%), 21(52.5 \%)$ and $27(67.5 \%)$ of the examined kofta, panne and sushi samples. Regarding to the edibility of the examined ready to eat (RTE) samples in relation to its content of S. aureus, 11(27.5\%), 21(52.5\%) and 27(67.5\%) of the examined kofta, panne and sushi samples, respectively, were rejected for exceeding S. aureus permissible limit (not more than $10^{2} \mathrm{cfu} / \mathrm{gm}$ ). The results also recorded the main values of $S$. aureus counts in the examined kofta, panne and sushi samples were $9.41 \times 10^{2} \pm 2.12 \times 10^{2}, 3.27 \times 10^{3} \pm 0.54 \times 10^{3}$ and $5.86 \times 10^{3} \pm 0.97 \times 10^{3} \mathrm{cfu} / \mathrm{g}$, respectively. Moreover the incidence for $S$. aureus enterotoxins positive samples, revealed that SE-A was $1(2.5 \%), 2(5 \%)$ and $4(10 \%)$ of the examined kofta, panée and sushi samples, respectively; while SE-B was detected in 1(2.5\%) of chicken panée only, while not detected in kofta and sushi samples, SE-D was detected in 1(2.5\%) each of kofta and sushi sample, while not detected in panne, SE-A+C was detected in 1(2.5\%) of kofta samples while not detected in panne and sushi samples, SE-A+D were detected in $1(2.5 \%)$ each of panne and sushi samples while not detected in kofta samples. Overall, 3(7.5\%), 4(10\%) and $6(15 \%)$ of the examined kofta, panne and sushi. Wherever to the highly obtained results of the $S$. aureus prevalence, especially enterotoxigenic strains; it encourages investigation of the antibiotic resistance profile molecularly against erythromycin (ermA), gentamicin (aac 6aph 2), methicillin ( $m e c A$ ) and vancomycin (vanA) resistance genes in randomly collected five $S$. aureus isolates of each sample and results revealed that out of the examined 15 isolates, $8(53.3 \%), 5(33.3 \%), 4(26.6 \%)$ and 2(13.3\%) were harbored ermA, aac 6-aph 2, mecA and vanA resistance genes, where sushi isolates had the highest prevalence of antibiotic resistance followed by panée and kofta samples, respectively.
\end{abstract}

\section{INTRODUCTION}

Pathogenic microorganisms are widely present in soil, water, animals and people. It presents on hands, cloths, utensils and cutting boards, the slight contact can transfer them to meat and cause food-borne diseases. Moreover, Raw food, especially meat, poultry and their extracts have dangerous microorganisms can be transferred into other food during preparation, handling and storage (FAO/WHO,2003 and Hanson et al., 2011).

Meat meals can be exposed to several ways of contamination through improper practices during production, storage and handling. This risk of contamination to these meals increasing by storage of food at ambient temperature, by using insufficiently high temperature for re-heating the food and also adding contaminated ingredients at stage which no further heat treatment applied (Ehirl et al., 2001).
The risk of bacterial food-borne disease also increases when meat meals were prepared in kitchens of student accommodation, youth hostels and shared homes. This increase of the risk may be due to high number of individuals who work in the kitchens without take care the safety issues and follow hygienic regulation.

Poisoning bacteria grow in food rapidly in the danger zone, so handlers are advised to never leave food out of refrigeration more than two hours. in case of the temperature is above $32^{\circ} \mathrm{C}$, food must not be left out more than one hour (FSIS, 2008).

$S$. aureus consider the main source of bacterial contamination in cooked meat due to workers handling during preparation and processing of it (FSIS, 2013). In addition, S. aureus were detected in 359 outbreaks and sporadic cases in the United Kingdom for production of

* Corresponding author: osabass-haccp@hotmail.com 
enterotoxin and recorded that meat and meat-based dishes was the vehicle of $75 \%$ of the incidents (FAO/WHO,2003). Antibiotic resistance is a global public health threat emerged vigorously in the last decades which attributed mainly to wiseless administration of antibiotics. Staphylococcus aureus is one of main reported multi-drugs resistant bacteria (MDR) that has been attributed to the presence of some antibiotic resistant genes, especially $m e c A$ gene which encoded penicillin-binding protein (Tambekar et al., 2011). PCR technology is the most promising due to rapidity, economical and sensitivity, since it can detect many microorganisms in clinical samples. Recently, specific oligonucleotide primers for PCR have been described for analysis of multi-drugs resistant $S$. aureus strains (Becket al., 2006).

Therefore, the current study was planned out to evaluate $S$. aureus count and detection the enterotoxins of some examined meat meals in Egyptian hotels through the following:

1- Determination of Staphylococci counts.

2- Detection and types of Staphylococcus species.

3- Detection and typing of enterotoxin.

4-Molecular detection of some antibiotic resistant genes in some isolated $S$. aureus strains.

\section{MATERIAL AND METHODS}

Preparation and collection of samples:

A total of 120 random meat meal samples represented by beef kofta, chicken panne, and fish-based meal (sushi) (40 of each) served in the Egyptian hotels located in Cairo governorate, Egypt was collected. Because the Egyptian hotels serve hundreds of RTE (thermally treated or not) food items, the selected samples were obtained to investigate $S$. aureu and their toxins and assess the health risk of them.

Preparation (ISO 6887-1, 2017):

Prepare 25 grams of examined sample, then add $225 \mathrm{ml}$ of sterile peptone water were added and thoroughly mixed using homogenizer for 2 minutes, from which ten-fold serial dilutions prepared. The prepared samples were subjected to the following examinations:

Determination of $S$. aureus counts (ISO 6888-1:1999, A1:2003):

$0.1 \mathrm{ml}$ from each of the previously prepared dilutions was spread over Baird Parker agar plate. The inoculated and control plates were incubated at $37^{\circ} \mathrm{C} / 48$ hours. black, shiny, circular, smooth, convex colonies with narrow white margin and surrounded by a clear zone extending into opaque medium were enumerated (suspected $S$. aureus) and total count/g was calculated. Then these colonies were picked up and purified on Semi-solid agar slopes for morphological examination and biochemical identification. Identification of detected strains:

1. Morphological identification (ISO 6888-1:1999, A1:2003).

2. Biochemical test for identification (MacFaddin, (2000):

3. Detection and typing of enterotoxin (Shingaki et al., 1981):

4. Polymerase Chain Reaction (PCR) (Perez et al., 2001):

\section{RESULTS}

Table 1 Incidences of Staphylococcus species isolated from examined samples $(\mathrm{n}=40)$

\begin{tabular}{l|lllllll}
\hline \multicolumn{1}{c}{ Beef Kofta } & \multicolumn{2}{l}{ Beef Kofta } & \multicolumn{2}{l}{$\begin{array}{l}\text { Chicken } \\
\text { Panne }\end{array}$} & Sushi Fish \\
\hline Strains & No. & $\%$ & No. & $\%$ & No. & $\%$ \\
\hline S. aureus & 13 & 32.5 & 21 & 52.5 & 27 & 67.5 \\
S. epidermidis & 10 & 25 & 15 & 37.5 & 18 & 45 \\
S. intermedius & 1 & 2.5 & 4 & 10 & 7 & 17.5 \\
S. saprophyticus & 0 & 0 & 3 & 7.5 & 2 & 5 \\
S. xylosus & 5 & 12.5 & 1 & 2.5 & 4 & 10 \\
\hline
\end{tabular}

Table 2 Staphylococcus aureus count/g in the examined meat meal samples $(\mathrm{n}=40)$

\begin{tabular}{llll}
\hline Meal & Min & Max & Mean \pm S.E \\
\hline \multirow{2}{*}{ Beef Kofta } & \multirow{2}{*}{$1.0 \times 10^{2}$} & $4.0 \times 10^{3}$ & $9.41 \times 10^{2} \pm$ \\
& & & $2.12 \times 10^{2}$ \\
Chicken Panne & $2.0 \times 10^{2}$ & $9.0 \times 10^{3}$ & $3.27 \times 10^{3} \pm$ \\
& & & $0.54 \times 10^{3}$ \\
Sushi Fish & $5.0 \times 10^{2}$ & $3.0 \times 10^{4}$ & $5.86 \times 10^{3} \pm$ \\
& & & $0.97 \times 10^{3}$ \\
\hline
\end{tabular}

Table 3 Edibility of the examined samples of meals served in the Egyptian hotels based on their contamination with $S$. aureus $(n=40)$.

\begin{tabular}{llllll}
\hline $\begin{array}{l}\text { Accepted } \\
\text { samples }\end{array}$ & \multicolumn{2}{l}{$\begin{array}{l}\text { Accepted } \\
\text { samples }\end{array}$} & \multicolumn{2}{l}{$\begin{array}{l}\text { Unaccepted } \\
\text { samples }\end{array}$} & $\begin{array}{l}\text { Staph. } \\
\text { Meareus/g* }\end{array}$ \\
\hline Beef Kofta & 29 & 72.5 & 11 & 27.5 & $\geq 10^{2}$ \\
Chicken & 19 & 47.5 & 21 & 52.5 & $\geq 10^{2}$ \\
Panne & 13 & 32.5 & 27 & 67.5 & $\geq 10^{2}$ \\
Sushi Fish & 13 & $51 \%$ & 59 & $49 \%$ & \\
Total & 61 & $51 \%$ &
\end{tabular}

*Egyptian Organization for Standardization (2005)

Table 4 Incidences of $S$. aureus enterotoxin isolated from meals served in the Egyptian hotels

\begin{tabular}{lllllll}
\hline Enterotoxin & \multicolumn{2}{l}{ Beef Kofta } & \multicolumn{2}{l}{ Chicken } & \multicolumn{2}{l}{ Sushi Fish } \\
& No & $\%$ & No & $\%$ & No & $\%$ \\
\hline A & 1 & 2.5 & 2 & 5 & 4 & 10 \\
B & - & - & 1 & 2.5 & - & - \\
D & 1 & 2.5 & - & - & 1 & 2.5 \\
A+C & 1 & 2.5 & - & - & - & - \\
A+D & - & - & 1 & 2.5 & 1 & 2.5 \\
Total & 3 & $7.5 \%$ & 4 & $10 \%$ & 6 & $15 \%$ \\
\hline
\end{tabular}

Table 5 Incidence of antibiotic resistant genes of $S$. aureus using multiplex PCR (15 strains)

\begin{tabular}{|c|c|c|c|c|c|c|c|c|c|}
\hline \multirow{2}{*}{\multicolumn{2}{|c|}{$\begin{array}{l}\text { Antibiotic } \\
\text { resistant } \\
\text { genes }\end{array}$}} & \multirow{2}{*}{$\begin{array}{c}\begin{array}{l}\text { No of } \\
\text { strains }\end{array} \\
\%\end{array}$} & \multicolumn{2}{|c|}{$\operatorname{van} A$} & \multicolumn{2}{|l|}{ mecA } & $\begin{array}{l}a a c(6)- \\
a p h\end{array}$ & \multicolumn{2}{|c|}{ ermA } \\
\hline & & & No. & $\%$ & $\begin{array}{l}\mathrm{N} \\
\mathrm{o} .\end{array}$ & $\%$ & No. & $\%$ & \\
\hline Beef & 5 & 0 & 0 & 2.5 & 1 & 0 & 0 & 2.5 & 1 \\
\hline $\begin{array}{l}\text { Kofta } \\
\text { Chick } \\
\text { en } \\
\text { n }\end{array}$ & 5 & 2.5 & 1 & 0 & 0 & 2.5 & 1 & 7.5 & 3 \\
\hline $\begin{array}{l}\text { Panne } \\
\text { Sushi } \\
\text { Fish }\end{array}$ & 5 & 2.5 & 1 & 7.5 & 3 & 10 & 4 & 10 & 4 \\
\hline Total & 15 & $5 \%$ & 2 & $10 \%$ & 4 & $12.5 \%$ & 5 & $20 \%$ & 8 \\
\hline
\end{tabular}

\section{DISCUSSION}

Staphylococcus aureus are carried on human hands, nasal passages and throats. Most food borne illness outbreaks are a result of contamination from food handlers and production of heat stable toxins in the food, bad sanitary food handling and improper cooking sources of Staphylococcal illnesses (FSIS 2003). 
Food handlers carrying enterotoxin-producing $S$. aureus in their noses or on their hands are regarded as the main source of food contamination, by manual contact or through respiratory secretions. $S$. aureus is a common present in the skin and mucosal membranes of humans, (Kluytmans et al., 2005).

Staphylococcus species had been investigated in the examined samples. The results recorded intable (1) revealed that detection of $S$. aureus, $S$. epidermidis, $S$. intermedius, $S$. saprophyticus and S. xylosusin 61(50.83\%), 43(35.83\%), $12(10 \%), 5(4.16 \%)$ and $10(8.33 \%)$ of the examined samples; where pathogenic S. aureus was detected in $13(32.5 \%)$, $21(52.5 \%)$ and $27(67.5 \%)$ of the examined kofta, panne and sushi samples with mean counts of $9.41 \times 10^{2} \pm 2.12 \times 10^{2}$, $3.27 \times 10^{3} \pm \quad 0.54 \times 10^{3}$ and $\quad 5.86 \times 10^{3} \pm \quad 0.97 \times 10^{3} \mathrm{CFU} / \mathrm{g}$, respectively (Table 2 ).

Regarding to the previously recorded results, Hassan et al. (2015) (26.67\% of the examined kofta samples), Hassanin et al. (2015) (60\% of the examined RTE kofta samples), Liang et al. (2016) who detected S. aureus in $34.2 \%$ of the examined sushi samples with mean count of $1.9 \times 10^{2}$ CFU/g), Shaltout et al. (2018) (56.6\% of the examined panne samples), Saif (2019) (5.2x10 CFU/g with prevalence of $56.6 \%$ of the examined kofta samples), and Gaafar (2020) $\left(12 \times 10^{3}\right.$ and $9.2 \times 10^{3} \mathrm{CFU} / \mathrm{g}$ with prevalence of 40 and $36.6 \%$ of kofta and panne samples, respectively). On the other hand, Hoel et al. (2015) (did not detect $S$. aureus in the examined sushi samples).

Referring to the edibility of the examined RTE samples in relation to its content of S. aureus, 11(27.5\%), 21(52.5\%) and $27(67.5 \%)$ of the examined kofta, panne and sushi samples were rejected for exceeding $S$. aureus permissible limit (not more than $10^{2} \mathrm{CFU} / \mathrm{g}$ ) (Table, 3).

Variation between authors may be referred to differences in personal hygiene, storage, temperature and handling conditions, staphylococcal food poisoning is the result of performed heat stable enterotoxins that are produced by certain strains of $S$. aureus resulting in symptoms of food intoxication. The main enterotoxins involved in SFP are sea (Staphylococcal enterotoxins A), seb (Staphylococcal enterotoxins B), sec (Staphylococcal enterotoxins C), sed (Staphylococcal enterotoxins D) and see (Staphylococcal enterotoxins E) (Chiang et al., 2008).

Table (4) showed the incidence of SEs detection in positive samples; the results revealed detection of SE-A in 1(2.5\%), $2(5 \%)$ and $4(10 \%)$ of the examined kofta, panne and sushi samples, respectively; while SE-B was detected in $1(2.5 \%)$ of chicken panne only while not detected in kofta and sushi samples, SE-D was detected in 1(2.5\%) of kofta and sushi samples of each while not detected in panne samples, SE$\mathrm{A}+\mathrm{C}$ was detected in $1(2.5 \%)$ of kofta samples while not detected in panne and sushi samples, SE-A+D were detected in $1(2.5 \%)$ each of panne and sushi samples while not detected in kofta samples. Overall, 3(7.5\%), 4(10\%) and $6(15 \%)$ of the examined kofta, panne and sushi contained SEs; in addition, SE-A was the prominently detected SE which proved that SE-A is the most common staphylococcal enterotoxin detected in food samples as reported by Argudín et al. (2010).

Previous investigations conducted by Kim et al. (2011), Saif (2019), and Gaafar (2020) could detect SEs in RTE sushi, kofta and panne samples, respectively, where SEA was the most prominent detected enterotoxin.
Referring to the highly obtained results of the $S$. aureus prevalence, especially enterotoxigenic strains; it encourages investigation of the antibiotic resistance profile molecularly against erythromycin (ermA), gentamicin (aac 6-aph 2), methicillin ( mecA) and vancomycin (vanA) resistance genes in randomly collected five $S$. aureus isolates of each sample. Results revealed that out of the examined 15 isolates, $8(53.3 \%), 5(33.3 \%), 4(26.6 \%)$ and $2(13.3 \%)$ isolates harbored ermA, aac 6-aph 2, mecA and vanA resistance genes, where sushi isolates had the highest prevalence of antibiotic resistance followed by panne and kofta samples, respectively (Table, 5).

\section{CONCLUSION}

For the differences between different authors in the field of the bacteriological quality of the examined RTE samples may be referred to variation in the localities, time and conditions of collection, also, it may refer to variation in the personal hygiene, processing and storage conditions, and hygienic quality of the manufacturing facilities.

\section{REFERENCES}

1. Argudín, M. A.; Mendoza, M. C. and Rodicio, M. R. (2010): "Food poisoning and S. aureus enterotoxins". J. Toxins (Basel), 2(7): 1751-1773 .

2. Beck, P. and Graden-Robinson, J. (2006): "Is food in my kitchen a safety hazard?". Science Today, 147: 558560.

3. Chiang, Y. C.; Liao, W. W.; Fan, C. M.; Pai, W. Y.; Chiou, C. S. and Tsen, H. Y. (2008): "PCR detection of staphylococcal enterotoxins (SEs) N, O, P, Q, R, U, and survey of SE types in Staphylococcus aureus isolates from food-poisoning cases in Taiwan". Inter. J. Food Microbiol., 121(1): 66-73.

4. Ehirl, J.E.J.; Azubuike, M.C.; Ubbaonu, C.N.; Anyanwu, E.G., Lbe, K.M. and Ogbonna, M.O. (2001): Critical control points of complementary food preparation and handling in eastern Nigeria. Bull World Health Organ., 79 (5):423 - 433.

5. FAO/WH (Food and Agriculture Organization of the United Nations and world Health Organization) (2003): Assuring food safety and quality: guidelines for strengthening national food control systems. Rome

6. Food Safety and Inspection service "FSIS" (2013): United states Department of Agriculture; Meat preparation: Beef from farm to table. Washington. DC. 20250-370.

7. FSIS "Food Safety and Inspection Service"/ USDA "Untied States Department of Agriculture" (2008): FSIS issues public health alert for frozen, stuffed raw chicken https://www.fda.gov/media/71976/download. products.

8. Gaafar, R. (2020): Prevalence of some food poisoning bacteria in some ready to eat sandwiches. Thesis, Ph.D. of Vet. Med. (Food Hygiene), Benha Univ., Egypt .

9. Hanson, B. M.; Dressler, A. E.; Harper, A. L.; Scheibel, R. P.; Wardyn, S. E.; Roberts, L. K.; Kroeger, J. S. and Smith, T.C. (2011): "Prevalence of S. aureus and MRSA on retail meat in Iowa". J. Infect. Public Health, 4(4):169-174.

10. Hassan, M. A., Amin, R. and El-Salhy, M. S. (2015): Bacteriological and Chemical Evaluation of Meat Meals in Some Egyptian Hotels. Benha Vet. Med. J., 29(2): 80-91. 
11. Hassanin R. Z. Tarabees, Abd El Rahman M. El Bagoury (2015) : Polymerase Chain Reaction (PCR): An Alternative Rapid Method for Detection of Some Microbial Contamination of Meat Products, lexandria Journal of Veterinary Sciences 2015, 45: 91-98 ISSN 1110-2047,

12. ISO "International Organization for Standardization (4833-1:2013): International Organization for Standardization. No.4833-1. Microbiology of the food chain-Horizontal method for the enumeration of microorganisms-Part 1 : Colony count at $30{ }^{\circ} \mathrm{C}$ by the pour plate technique.

13. ISO "International Organization for Standardization (6579-1:2017): International Organization for Standardization. No.6579-1. Microbiology of the food chain Horizontal method for the detection, enumeration and serotyping of Salmonella - Part1: Detection of Salmonella spp .

14. ISO "International Organization for Standardization (6887-1:2017): International Organization for Standardization. No.6887-1. Microbiology of the food chain - Preparation of test samples, initial suspension and decimal dilutions for microbiological examination, Part 1: General rules for the preparation of the initial suspension and decimal dilutions.

15. ISO "International Organization for Standardization" (16649-2:2001): International Organization for Standardization. No.16649-2. Microbiology of food and animal feeding stuffs - Horizontal method for the enumeration of glucuronidase-positive Escherichia coli - Part 2: Colony-count technique at $44{ }^{\circ} \mathrm{C}$ using 5bromo-4-chloro-3-indolyl-D-glucuronide.

16. ISO "International Organization for Standardization"(4832:2006): International Organization for Standardization. No.4832. Microbiology of food and animal feeding stuffshorizontal method for the enumeration of coliforms: colony count technique.

17. ISO "International Organization for Standardization" (6888-1:1999, A1:2003): International Organization for Standardization. No. 6888-1:1999, A1:2003. Microbiology of food and animal feeding stuffs Horizontal method for the enumeration of coagulasepositive staphylococci (Staphylococcus aureus and other species) - Part 1: Technique using Baird-Parker agar medium (includes amendment A1:2003).

18. Kim, J. S., E. Kuk, K. N. Yu, J.-H. Kim, S. J. Park, H. J. Lee, S. H. Kim, Y. K. Park, Y. H. Park, et al. (2011). Antibacterial Activity of Silver-nanoparticles Against Staphylococcus aureus and Escherichia coli, Microbiology and Biotechnology Letters), Volume 39 Is, page 77-85.

19. Kluytmans, J. A. and Wertheim, H. F. (2005): "Nasal carriage of Staphylococcus aureus and prevention of nosocomial infections". Infection, 33: 3-8 .

20. Liang. A. W. Long-LiPana. L (2016): The microbiological quality of take-away raw salmon finger sushi sold in Hong Kong, Food control, Volume 69, November 2016, Pages 45-50.

21. MacFaddin, J. F. (2000): "Biochemical tests for identification medical bacteria". Warery Press, INC., Baltimore, Md. 21202 USA.

22. Perez, E.; Claverie, M.; Villar, J. and Alvarez, M. (2001): Multiplex PCR for simultaneous identification of Staphylococcus aureus and detection methicillin and mupirocin resistance. J. Clin. Microbiol., 39 (11): 4037 $-4041$.

23. Saif, M. Z. (2019): Methicillin resistant Staphylococcus aureus in ready to eat meat products. Thesis, Master of Vet. Med. (Food Hygiene), Benha Univ., Egypt.

24. Shaltout, F. A., El Zahaby, D., Lotfy, L. and El-Shorah, H. (2018): Bacteriological status of chicken meat products marketed at Menofia governorate. Benha Vet. Med. J., 34(1): 28-40.

25. Shingaki M. R, Sally A.Rose, Pameles M. Stringer (1981): Detection of staphylococcal enterotoxins in dairy products by the reversed passive latex agglutination (SET-RPLA) kit: International Journal of Food Microbiology, Volume 8, Issue 1, February 1989, Pages 65-72.

26. Tambekar, D. H.; Kulnari, R. V.; Shirsat, S. D. and Bhadange, D. G. (2011): "Bacteriological quality of street vended food: A case study of Amravati city (MS) India”. Biosci. Discov., 2:350-354. 